\title{
Anatomical versus non-anatomical configuration of double coraco-clavicular tunnel technique in acromioclavicular joint reconstruction
}

\author{
Tobias Schöbel $^{1}$ - Jan Theopold ${ }^{1}$. Jean-Pierre Fischer ${ }^{2} \cdot$ Sabine Löffler $^{3} \cdot$ Stefan Schleifenbaum ${ }^{2} \cdot$ Pierre Hepp $^{1}$
}

Received: 17 October 2020 / Accepted: 2 April 2021 / Published online: 21 April 2021

(c) The Author(s) 2021

\begin{abstract}
Purpose Horizontal instability is a common problem after acromioclavicular joint injuries. The aim of this study was to evaluate if there is a difference regarding horizontal stability between an anatomical and a non-anatomical configuration of the double tunnel coraco-clavicular ligament reconstruction of the acromioclavicular joint.

Methods Thirteen acromioclavicular joints of human cadaveric shoulders in ethanol-glycerin fixation were included in the study and underwent cyclic anterior and posterior translational testing at a load of $70 \mathrm{~N}$ using an electromechanical uniaxial testing machine. The shoulders were randomly assigned to the following groups: double coraco-clavicular tunnel technique in an anatomical configuration (DCTa) and double coraco-clavicular tunnel technique in an inverse configuration of the anatomical position (DCTb). The dislocation was recorded with a 3D optical measuring system.

Results The total horizontal displacement $\left(p_{10}=0.0221 ; p_{5000}=0.082\right)$ was significantly higher for the non-anatomical reconstruction (DCTb) compared to the anatomical reconstruction (DCTa) after every measured amount of cycles. The increase in displacement for DCTb group was overall higher than the increase in displacement for DCTa group but without significance. Conclusion Reconstruction of the CC ligaments in an anatomical configuration with two suture devices results in a significantly higher stability of the AC joint in the horizontal plane than reconstruction of the CC ligaments in a non-anatomical configuration. Based on the results of this biomechanical in vitro study, the use of a double coraco-clavicular reconstruction should focus on an anatomically correct position of the suture devices.
\end{abstract}

Keywords Acromioclavicular joint/injuries/surgery · Arthroscopy/methods · Cadaver · Joint instability/surgery · Ligaments $\cdot$ Articular/surgery $\cdot$ Humans $\cdot$ Joint dislocation $\cdot$ Anatomy

\section{Introduction}

Tobias Schöbel and Jan Theopold author have contributed equally to this publication.

Pierre Hepp

pierre.hepp@medizin.uni-leipzig.de

Tobias Schöbel

tobias.schoebel@medizin.uni-leipzig.de

Jan Theopold

jan.theopold@medizin.uni-leipzig.de

Jean-Pierre Fischer

jean-pierre.fischer@zesbo.de

Sabine Löffler

sabine.loeffler@medizin.uni-leipzig.de
Acromioclavicular (AC) joint dislocations are common and add up to $9 \%$ of traumatic shoulder injuries [1,2]. High-grade AC joint dislocations result in a disruption of the AC joint, the coracoclavicular (CC) ligaments and the

Stefan Schleifenbaum

stefan.schleifenbaum@medizin.uni-leipzig.de

1 Department of Orthopedic, Trauma and Plastic Surgery, University of Leipzig, Liebigstraße 20, 04103 Leipzig, Germany

2 ZESBO - Zentrum zur Erforschung der Stuetz- und Bewegungsorgane, Semmelweisstrasse 14, 04103 Leipzig, Germany

3 Institute of Anatomy, University of Leipzig, Liebigstraße 13, 04103 Leipzig, Germany 
deltotrapezoid (DT) fascia. The present study focusses on the CC ligaments. In recent years, the surgical treatment for high-grade AC joint dislocation was focused on an anatomical reconstruction of the $\mathrm{CC}$ ligaments [3-5]. CC augmentations with synthetic, non-absorbable suture-button-devices were used to mimic the anatomical and biomechanical characteristics of the CC ligaments [6-8]. Unsatisfying results after reconstruction are often based on remaining or recurring instabilities of the horizontal plane of the AC joint $[9$, 10] Biomechanical and clinical studies have shown the superiority of double button fixations in comparison to single button fixations $[6,11,12]$. However, the exact placement of both constructions might be difficult in clinical practice due to soft tissue coverage, limited surgical exposition and the anatomical variability. To avoid repeated drilling, possibly resulting in a fracture of the coracoid, other trajecteories may be accepted as a compromise [13-15]. Furthermore, no statistically significant difference in the clinical and radiological outcomes between an anatomical reconstruction of the $\mathrm{CC}$ ligaments in a $\mathrm{V}$-shaped configuration and $\mathrm{CC}$ reconstruction in a parallel configuration was found [16]. To our knowledge, no biomechanical study investigating the influence of the position of the CC ligaments on the stability of the AC joint exists.

Thus, the aim of this in vitro study was to evaluate whether there is a biomechanical difference between an anatomical and a non-anatomical configuration of CC ligament reconstruction using the double tightrope technique. The hypothesis was, that a $\mathrm{CC}$ ligament reconstruction using a double coraco-clavicular tunnel technique (DCT) reconstruction in an anatomical configuration would show more stability in the horizontal plane of the AC joint compared to a non-anatomical configuration of the implants. As a nonanatomical configuration, we chose a mirror-inverted reconstruction of the ligaments, thereby attempting to minimize the effects of mutual inhibition of the CC ligaments.

\section{Material and methods}

\section{Specimen preparation}

A total of 13 cadaveric shoulder specimens, 7 right, 6 left shoulders (not matched), from eight human cadavers (3 female and 5 male) were obtained in ethanol-glycerinfixed condition [17] and were kept at a temperature of $4{ }^{\circ} \mathrm{C}$. The specimens were examined visually before preparation, specimens with visible degeneration or post-injury status of the AC joint were excluded from the examination $(n=3)$. The mean age was $84.8 \pm 7.5$ years. Soft tissues including the deltotrapezoid fascia were removed from all specimens, leaving only the ligaments and capsule around the $\mathrm{AC}$ joint to maintain the original anatomic position of the clavicle. The inferior part of the scapula was secured in a custom block mold to the inferior edge of the glenoid cavity, using alabaster modeling plaster. The presented test model of an AC cerclage was used as a standard [12]. Its effect is not part of the present investigation.

Two groups were investigated:

- DCTa group $(n=7)$ : DCT technique in an anatomical configuration as a control (Fig. 1).

- DCTb group $(n=6)$ DCT technique in a non-anatomical configuration as the observer group (Fig. 2).

The specimens were randomly assigned to each group.

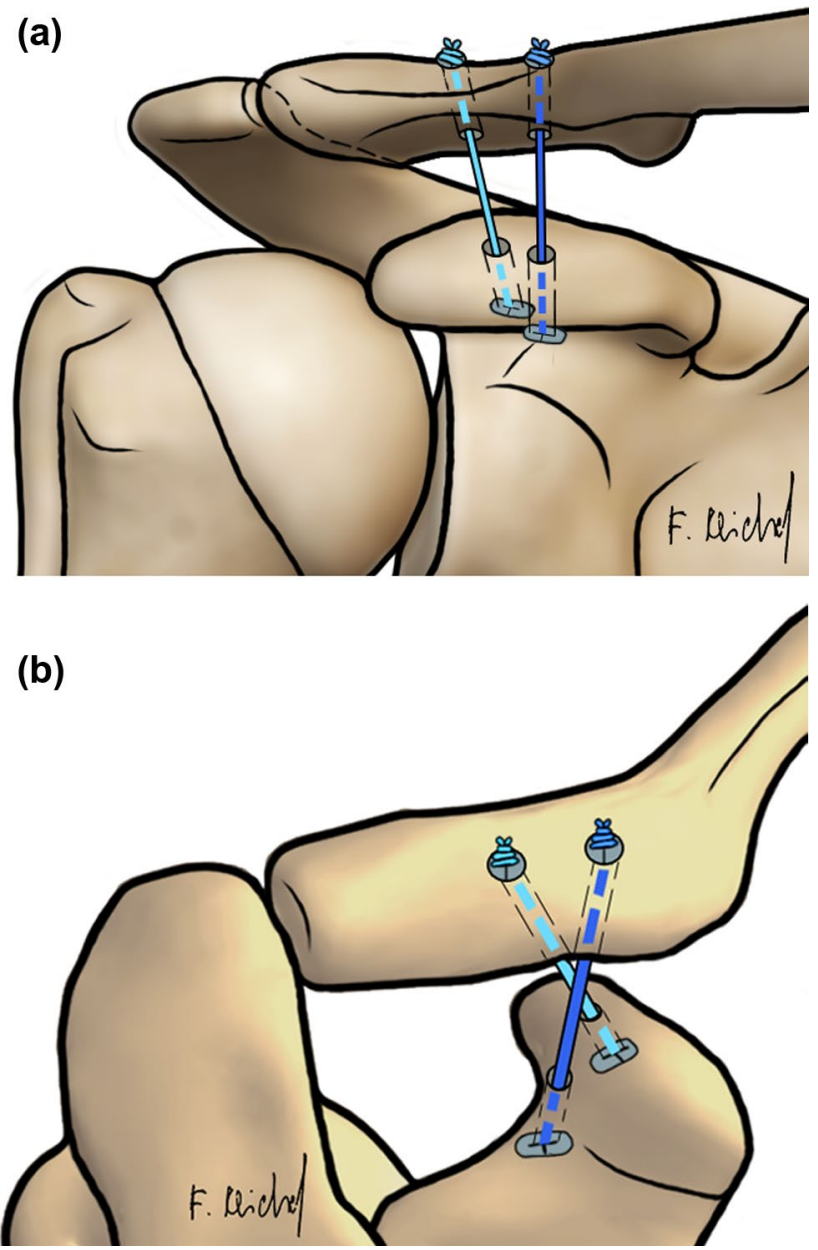

Fig. 1 Coracoclavicular ligament reconstruction for the DCT technique with horizontal augmented AC FiberTape ${ }^{\circledR}$ cerclage. a Schematic anteroposterior (AP) view on the AC joint. b Schematic dorsal view on the AC joint. $D C T$ double clavicular tunnel; $A C$ acromioclavicular 


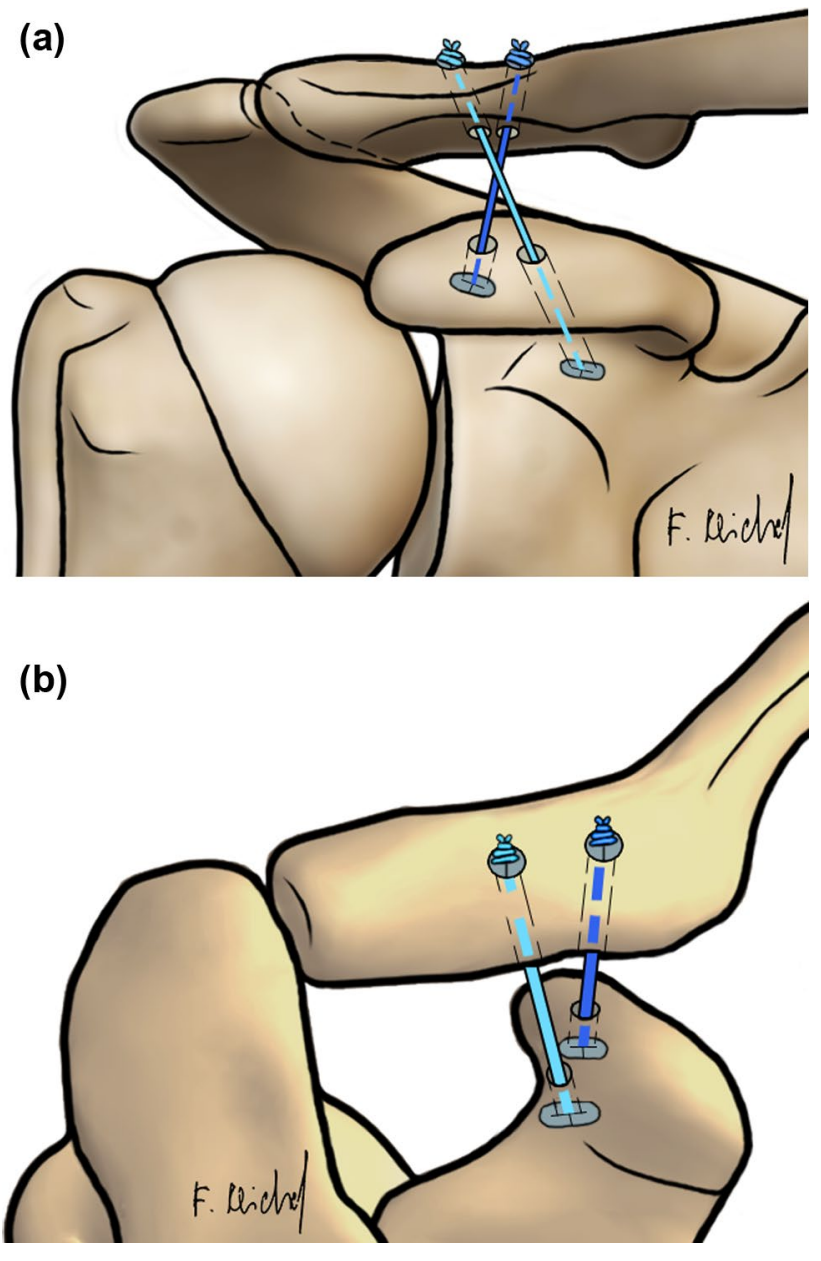

Fig. 2 Coracoclavicular ligament reconstruction for the DCT technique in non-anatomical configuration with horizontal augmented AC FiberTape ${ }^{\circledR}$ cerclage. a Schematic anteroposterior (AP) view on the AC joint. b Schematic dorsal view on the AC joint. DCT double clavicular tunnel; $A C$ acromioclavicular

\section{Reconstruction techniques}

All surgical reconstructions were performed by one experienced surgeon.

The CC ligaments, AC ligaments and the AC capsule were transected. For both techniques, the length of the clavicle had been measured according to Rios et al. [18]. A $20 \%$ mark of the total length was set from the lateral edge of the clavicle.

DCTa group: For the DCT technique in an anatomical configuration, a guide was used to drill two $2.4 \mathrm{~mm}$ pins from the clavicle to the coracoid process. The first drill (trapezoidal position) started $5 \mathrm{~mm}$ lateral of the $20 \%$ mark of the clavicle and ended $10 \mathrm{~mm}$ dorsal of the ventral edge of the coracoid process. The second drill (conoidal position) started $5 \mathrm{~mm}$ medial of the $20 \%$ mark of the clavicle, perforating the midpoint of a line between the

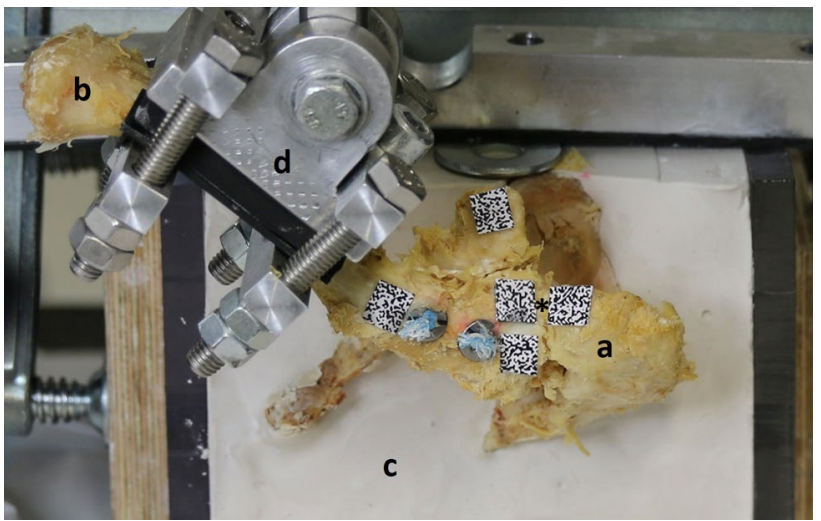

Fig. 3 Test setting: Reconstructed specimens (DCT) in the uniaxial testing machine. Acromion (a), Clavicle (b), block mold (c), mounting device (d) and $\mathrm{AC}$ joint (*)

base of the coracoid process and the neck of the scapula. Both pins were over reamed with the $4 \mathrm{~mm}$ cannulated drill. Using passing wires, the suture button devices were passed through the tunnels and tied together over the clavicular button (Fig. 1) [19, 20]. DCTb group: For the DCT technique in a non-anatomical configuration, the configuration was mirrored: The first drill started $5 \mathrm{~mm}$ lateral of the $20 \%$ mark of the clavicle and ended in the middle of the line between the base of the coracoid process and the neck of the scapula. The second drill started $5 \mathrm{~mm}$ medial of the $20 \%$ mark of the clavicle and ended $10 \mathrm{~mm}$ dorsal of the ventral edge of the coracoid process bottom. Both pins were reamed with the $4 \mathrm{~mm}$ cannulated drill. The further procedure was performed as described for DCTa group (Fig. 2).

\section{Biomechanical testing}

The specimens underwent cyclic testing using an electromechanical, uniaxial testing machine (Instron 5566A, Instron $\mathrm{GmbH}$, Darmstadt, Germany). In contrast to other studies [3-5, 8, 21, 22], we used an optical 3D measurement system (Q400 Digital Image Correlation System, LIMESS Messtechnik und Software GmbH, Krefeld, Germany to record images of the resulting displacements (in $\mathrm{mm}$ ) after a standardized amount of cycles $(10,100,500,1000,2500$ and 5000) during the tests for each specimen. This allows a determination of the displacement at the AC-joint without the influence of bending processes of the bone or fixation material. For this purpose, the clavicle length was measured [18] and the midpoint of the clavicle was fixed to the testing machine's traverse using a customized mounting device. This customized mounting device enabled various angle settings in order to meet the anatomical variation of the cadaveric specimens examined (Fig. 3). 
The optical 3D measurement system required markers with random speckle patterns that were attached to the surface of clavicle and scapula at relevant points (Fig. 4).

Based on previous studies, a testing load of $70 \mathrm{~N}$ was applied cyclically in anterior and posterior direction $[4,8$, 21-24]. The first 10 cycles were used for precondition before commencing measurements $[4,8]$. In total, 5000 cycles were run to monitor a possible change in the displacement between the groups. The induced traverse motion was forcecontrolled with a testing speed of $5 \mathrm{~mm} / \mathrm{s}$. Throughout the experiment, ethanol-glycerin-solution was applied to prevent tissue dehydration.

Speckle pattern marks respectively $2 \mathrm{~mm}$ lateral and medial of the AC joint line (Fig. 4) were used to measure the AC joint's horizontal displacement. Analysis of optical data from 1932 images per specimen (Fig. 5), obtained throughout the entire course of testing, was performed using the Instra4D software (Dantec Dynamics A/S, Tonsbakken, Denmark).

While alive, all body donors gave their informed and written consent for the donation of their bodies for teaching

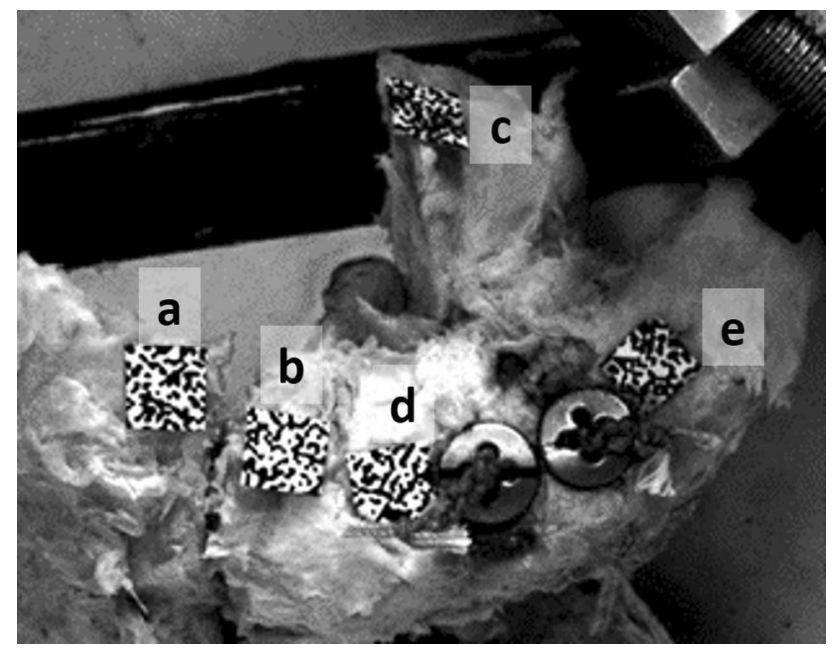

Fig. 4 AC joint reconstructed using the DCTa technique with the position of the speckle patterns: $2 \mathrm{~mm}$ lateral (a) and $2 \mathrm{~mm}$ medial (b) of the AC joint line, coracoid process (c), $10 \mathrm{~mm}$ (d) lateral and medial (e) of a $20 \%$ mark on the clavicle and research purposes, as part of the body donor program regulated by the Saxonian Death and Funeral Act of 1994. Institutional approval for the use of the post-mortem tissues of the donors was obtained. For this reason, there is no specific number from the ethics committee.

\section{Statistical analyses}

A power analysis was performed, using data from two previous studies with a comparable setup [4, 22]. For an alpha value of 0.05 and a power of 0.90 , a minimum of 6 specimens per group were needed. The absolute increase in displacement was calculated by subtracting the displacement measured after 10 cycles of a precondition from the displacement after each measured amount of cycles for each group respectively.

For statistical analysis, SPSS (version 24, SPSS Inc., Chicago, IL, USA) was used. The horizontal displacement of the unpaired specimens and the absolute increase in displacement for the groups was analyzed using the Mann-Whitney$U$-test. The alpha level was set to $p<0.05$ for the determination of significance.

\section{Results}

There was neither any hardware nor specimen failure in both groups. Precision of the recorded data was high with a measurement uncertainty of $\pm 2 \mu \mathrm{m}$.

The mean anterior translation $\left(p_{10}=0.0221 ; p_{100}=0.0350\right.$; $\left.p_{500}=0.0350 ; p_{1000}=0.0221 ; p_{2500}=0.0221 ; p_{5000}=0.0221\right)$ and the mean total displacement $\left(p_{10}=0.0221 ; p_{100}=0.0082\right.$; $p_{500}=0.0047 ; p_{1000}=0.0047 ; p_{2500}=0.0082 ; p_{5000}=0.0082$ ) for DCTb group was significantly higher after 10, 100, 500, 1000, 2500 and 5000 cycles compared to DCTa group (Table 1, Fig. 6). The specimens showed a total increase of $3.7 \mathrm{~mm}$ (relative increase 65\%) for the DCTa group and $6.2 \mathrm{~mm}$ (relative increase $72 \%$ ) for the DCTb group after 5000 cycles in comparison to the displacement after 10 cycles. The increase in displacement for DCTb group was overall higher than the increase in displacement for DCTa group but without a statistical significant difference for

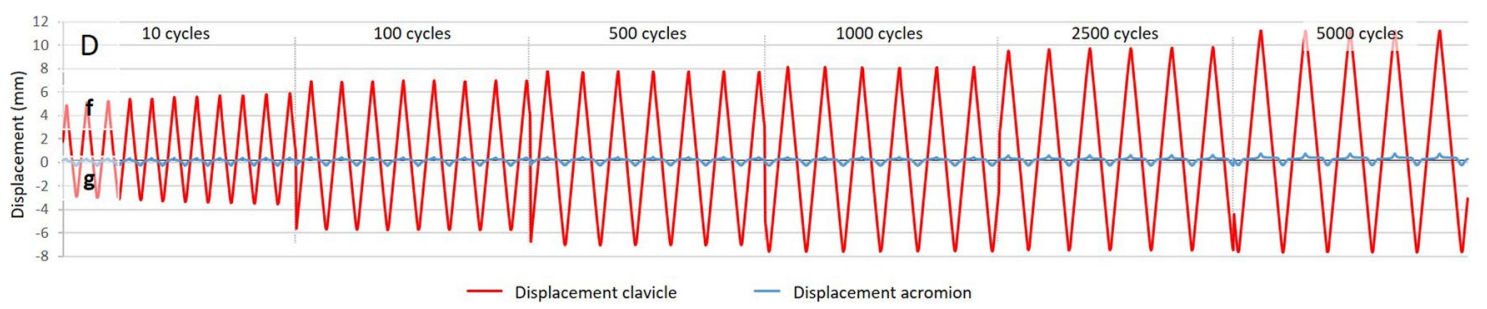

Fig. 5 Horizontal displacement in anterior (f) and posterior (g) direction over 5000 cycles 
Table 1 Mean horizontal displacement in anterior and posterior direction for the measured numbers of cycles for both groups

\begin{tabular}{llllll}
\hline Cycles $(n)$ & \multicolumn{2}{l}{ Anatomic reconstruction } & \multicolumn{2}{l}{$\begin{array}{l}\text { Non-anatomic reconstruc- } \\
\text { tion }\end{array}$} \\
\cline { 2 - 3 } \cline { 5 - 6 } \cline { 5 - 6 } & \multicolumn{2}{l}{ Mean displacement $(\mathrm{mm})$} & & \\
\cline { 2 - 3 } & Anterior & Posterior & Anterior & Posterior \\
\hline 10 & $2.93 \pm 1.00^{*}$ & $2.76 \pm 1.24$ & $4.61 \pm 1.30^{*}$ & $4.02 \pm 2.00$ \\
100 & $3.60 \pm 1.20^{*}$ & $3.48 \pm 1.20$ & $5.62 \pm 1.36^{*}$ & $5.71 \pm 2.31$ \\
500 & $3.91 \pm 1.22^{*}$ & $3.83 \pm 1.15$ & $6.12 \pm 1.51^{*}$ & $6.58 \pm 2.57$ \\
1000 & $4.06 \pm 1.24^{*}$ & $3.97 \pm 1.14$ & $6.43 \pm 1.68^{*}$ & $6.93 \pm 2.60$ \\
2500 & $4.53 \pm 1.43^{*}$ & $4.15 \pm 1.18$ & $6.97 \pm 1.65^{*}$ & $7.08 \pm 2.82$ \\
5000 & $4.90 \pm 1.55^{*}$ & $4.48 \pm 1.47$ & $7.65 \pm 1.93^{*}$ & $7.21 \pm 2.88$ \\
\hline
\end{tabular}

$* p<0,05$ for both groups

both groups $\left(p_{100}=0.1375 ; p_{500}=0.0734 ; p_{1000}=0.0734\right.$; $p_{2500}=0.1014 ; p_{5000}=0.0734$ ) (Fig. 7). For the DCTa group, there was a statistically significant increase in displacement after 50,000 cycles compared to 100 cycles $(p=0.0022)$ but the significance for the DCTb group $(p=0.0952)$.

\section{Discussion}

This present biomechanical study shows that the placement of the devices in double tight rope technique in accordance with the anatomic trajectories of the CC ligaments results in significantly higher stability in the horizontal plane of the AC joint compared to a non-anatomical configuration.

The anatomy of the CC ligaments is highly complex and meets the needs of the AC joint. The origin of the lateral trapezoid ligament has a mean distance of $24.9 \mathrm{~mm}$ to the lateral edge of the clavicle and it inserts at the top of the coracoid, The mean distance to the origin of the medial conoid ligament is $46.3 \mathrm{~mm}$, it inserts at the bottom of the coracoid $[11,18]$. The ligaments are cone-shaped and 2-3 times larger at their clavicular origins than at their insertions at the conoid [25]. Both ligaments have a mean length of $19.4 \mathrm{~mm}$ and are oriented in a V-shaped configuration [18, 25-28].

The conoid ligament resists high forces for anterior and posterior loads, the trapezoid ligament counteracts posterior loads [29]. These findings correspond to the suggestion of multiple authors, stating that that the ligaments should not be considered as a single structure in surgical reconstruction [28-30].

The presented study neither evaluates the biomechanical function of the individual ligaments nor the influence of the AC capsule, but the influence of the CC ligaments as a functional unit which provides a higher stability when reconstructed in an anatomical configuration.
Kraus et al. found no statistically significant differences between a $\mathrm{CC}$ reconstruction technique placing the coracoclavicular drill holes in a $\mathrm{V}$-shaped position compared to a $\mathrm{CC}$ reconstruction technique placing the drill holes in a parallel position regarding clinical and radiological results two years after surgical treatment [16]. Because of the inherent differences between a clinical and a biomechanical test setting and the differences between the groups tested, these results are only to a limited extend comparable to those from this presented study. Whereas Kraus et al. compared a more anatomical $\mathrm{CC}$ reconstruction technique in $\mathrm{V}$-shape to a rather less anatomical, parallel CC reconstruction, we compared an anatomically correct $\mathrm{CC}$ reconstruction technique mimicking the position of the conoid and trapezoid ligament to a $\mathrm{CC}$ reconstruction using an inverse configuration of the anatomical position. However, our results show that an anatomical position of the $\mathrm{CC}$ reconstruction devices may provide more stability in the horizontal plane of the $\mathrm{AC}$ joint.

Both groups showed an increased displacement during the cyclic load, without a statistically significant difference between the anatomic and non-anatomic configuration. This elongation is consistent with many biomechanical studies on that matter [12, 31, 32]. Schär et al. compared the horizontal and vertical stability in the AC Joint using Sawbone Specimen [32]. 2 of the 3 groups tested used a double coracoid reconstruction technique, resulting in similar elongation over 1,500 cycles. In the present study, the increase in displacement after 5,000 cycles compared to (after) 100 cycles was approximately equal, confirming their findings.

We assume that due to the specific position and cone shape of the CC ligaments and their V-shaped configuration $[18,25]$, there is a mutual inhibition of both ligaments, resulting in a higher stability in the horizontal plane of the AC joint. This assumption is supported by a study using a 3-Dimensional Finite Element Model to determine the change in length and tension of the $\mathrm{CC}$ ligaments during different positions of shoulder abduction by Seo et al. [33]. They showed that both components of the CC ligament function in a reciprocal mode during shoulder motions. In clinical practice, the effect of coracoid tunnel placement on the stability of the coracoid and AC joint is of importance, especially regarding techniques using the DCT-techniques with at least two coracoclavicular drill holes and exact anatomical placement. This is technically challenging and wrong placement or repeated drilling can result in a failure of the coracoid [13, 34], presumably discouraging surgeons from using these techniques. As an advanced solution, image-free navigated coracoclavicular drilling may enable a precise anatomical positioning of the drill holes [35], reducing the risk of iatrogenic coracoid fractures [36].

This study has the same inherent limitations as other cadaveric studies. (1) The surgical reconstruction technique used remains an approximation to an anatomical 

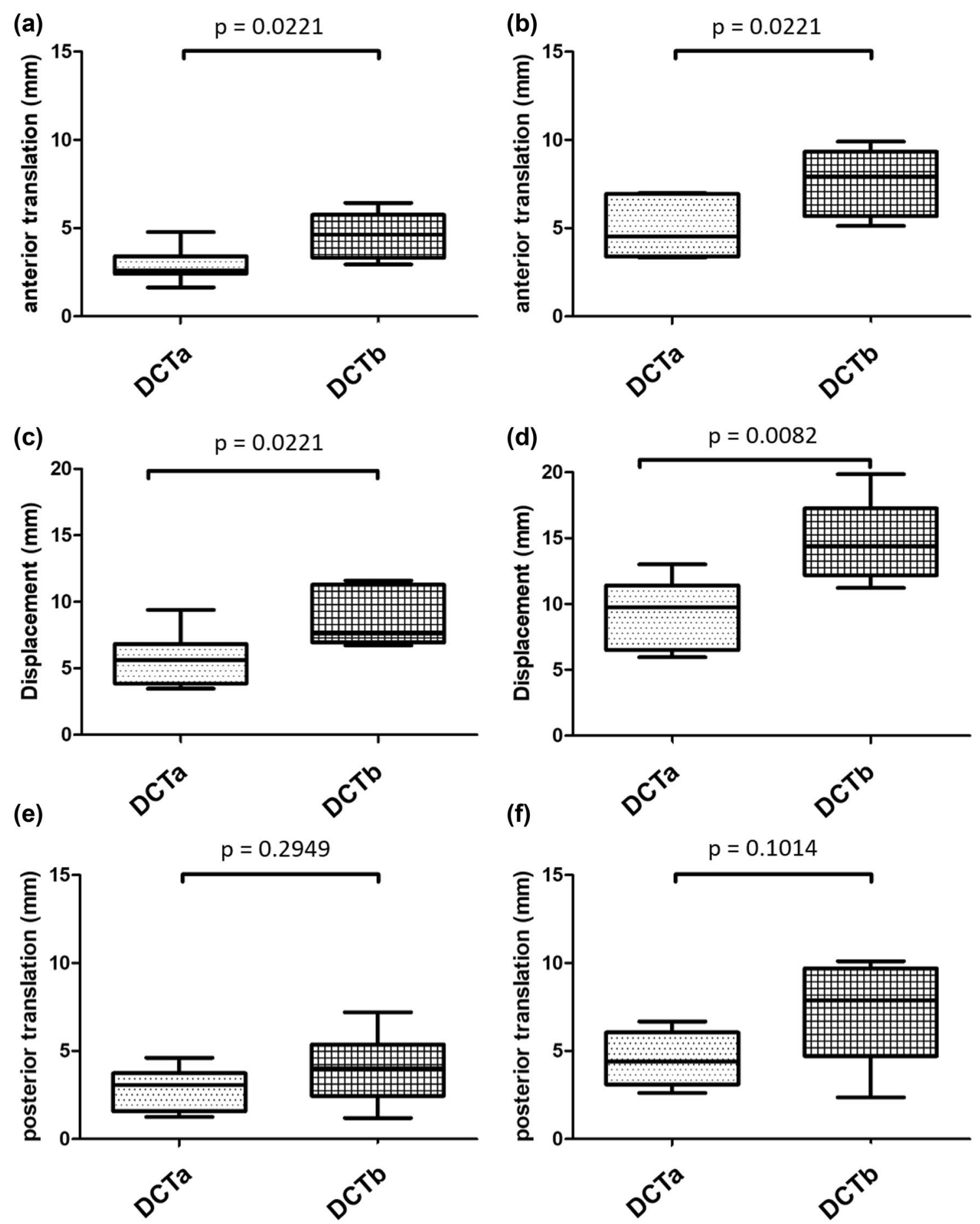

Fig. 6 Boxplots for horizontal translation: anterior translation after 10 (a) and after 5000 cycles (b), total displacement after 10 (c) and after 5000 cycles (d), posterior translation after 10 (e) and after 5000 cycles (f)

reconstruction and does not fully mimic the trajectories of the CC ligaments due to their highly complex anatomy. (2) The anatomical variations of the AC joint and the clavicle affect the fixation of the specimen as well as the surgical positioning and implementation of the suture button devices, thus they may influence the results of the 3D optical measuring system. (3) The biomechanical test setting is not fully transferable into clinical practice. (4) The donors' age and the ethanol-glycerin fixation: Anatomic coracoclavicular reconstructions are typically performed in young, healthy 


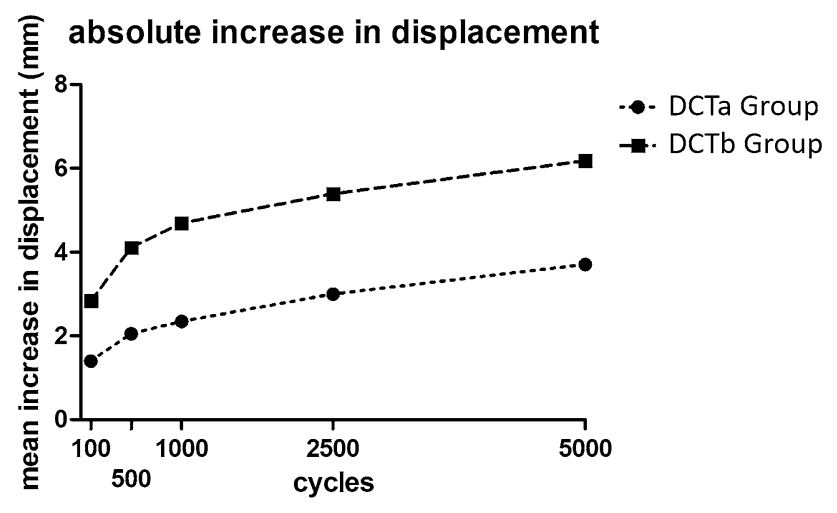

Fig. 7 Line graph: Difference of displacement in relation to displacement after precondition between both techniques in dependence of the cycles

patients with adequate bone mineral density. However, the specimens were chosen to account for anatomical variations which may not considerably change with age. Furthermore, the anatomy may not be altered by the method of fixation.

\section{Conclusion}

The significantly higher displacement in the horizontal plane and the higher increase of this displacement after a high number of cycles for the non-anatomical CC reconstruction technique in comparison to the anatomical reconstruction implies that an anatomical placement of reconstruction devices for $\mathrm{AC}$ joint displacements leads to a more beneficial biomechanical performance, at least in the horizontal plane.

Based on the results of this biomechanical in vitro study, the use of a double coracoid-clavicular reconstruction should focus on an anatomically correct position of the suture devices.

Acknowledgements We acknowledge the support from the Deutsche Arthrose Hilfe e. V.

Author contributions Conceptualization: JT, TS, SL, JPF, SS, PH. Methodology: JT, TS, JPF, SS, PH. Software: TS, JPF, SS. Validation: JT, TS, JPF, SS, PH. Formal analysis: JT, TS, JPF. Investigation: JT, TS, JPF. Writing (original draft preparation): JT, TS, SS, PH. Writing (review and editing): JT, TS, PH. Preparation of the donor material: SL. Supervision: SS, PH. Project administration: JT, SS, PH. Funding acquisition: JT, TS, PH.

Funding Open Access funding enabled and organized by Projekt DEAL.

\section{Declarations}

Conflict of interest The authors declare that they have no conflict of interest.
Ethical approval Institutional approval for the use of the post-mortem tissues of 126 the donors was obtained. For this reason there is no specific number from the ethics committee.

Informed consent Informed consent was obtained from all individual participants included in the study.

Open Access This article is licensed under a Creative Commons Attribution 4.0 International License, which permits use, sharing, adaptation, distribution and reproduction in any medium or format, as long as you give appropriate credit to the original author(s) and the source, provide a link to the Creative Commons licence, and indicate if changes were made. The images or other third party material in this article are included in the article's Creative Commons licence, unless indicated otherwise in a credit line to the material. If material is not included in the article's Creative Commons licence and your intended use is not permitted by statutory regulation or exceeds the permitted use, you will need to obtain permission directly from the copyright holder. To view a copy of this licence, visit http://creativecommons.org/licenses/by/4.0/.

\section{References}

1. Chillemi C, Franceschini V, Dei Giudici L et al (2013) Epidemiology of isolated acromioclavicular joint dislocation. Emerg Med Int 2013:171609. https://doi.org/10.1155/2013/171609

2. Mazzocca AD, Arciero RA, Bicos J (2007) Evaluation and treatment of acromioclavicular joint injuries. Am J Sports Med 35:316-329. https://doi.org/10.1177/0363546506298022

3. Abat F, Sarasquete J, Natera LG et al (2015) Biomechanical analysis of acromioclavicular joint dislocation repair using coracoclavicular suspension devices in two different configurations. J Orthop Traumatol 16:215-219. https://doi.org/10.1007/ s10195-015-0346-y

4. Beitzel K, Obopilwe E, Chowaniec DM et al (2011) Biomechanical comparison of arthroscopic repairs for acromioclavicular joint instability: suture button systems without biological augmentation. Am J Sports Med 39:2218-2225. https://doi.org/10.1177/ 0363546511416784

5. Walz L, Salzmann GM, Fabbro T et al (2008) The anatomic reconstruction of acromioclavicular joint dislocations using 2 TightRope devices: a biomechanical study. Am J Sports Med 36:2398-2406. https://doi.org/10.1177/0363546508322524

6. Grutter PW, Petersen SA (2005) Anatomical acromioclavicular ligament reconstruction: a biomechanical comparison of reconstructive techniques of the acromioclavicular joint. Am J Sports Med 33:1723-1728. https://doi.org/10.1177/0363546505275646

7. Baumgarten KM, Altchek DW, Cordasco FA (2006) Arthroscopically assisted acromioclavicular joint reconstruction. Arthroscopy 22:228.e1-228.e6. https://doi.org/10.1016/j.arthro.2005.12.026

8. Mazzocca AD, Santangelo SA, Johnson ST et al (2006) A biomechanical evaluation of an anatomical coracoclavicular ligament reconstruction. Am J Sports Med 34:236-246. https://doi.org/10. 1177/0363546505281795

9. Hann C, Kraus N, Minkus M et al (2017) Combined arthroscopically assisted coraco- and acromioclavicular stabilization of acute high-grade acromioclavicular joint separations. Knee Surg Sports Traumatol Arthrosc. https://doi.org/10.1007/s00167-017-4643-2

10. Scheibel M, Droschel S, Gerhardt C et al (2011) Arthroscopically assisted stabilization of acute high-grade acromioclavicular joint separations. Am J Sports Med 39:1507-1516. https://doi.org/10. 1177/0363546511399379

11. Patzer T, Clauss C, Kuhne CA et al (2013) Die arthroskopisch unterstutzte Stabilisierung der akuten AC-Gelenksprengung: 
Vergleich der klinischen und radiologischen Ergebnisse der Single- vs. Double-TightRope-Technik (Arthroscopically assisted reduction of acute acromioclavicular joint separations: comparison of clinical and radiological results of single versus double TightRope technique). Unfallchirurg 116:442-450. https://doi.org/ 10.1007/s00113-011-2135-2

12. Theopold J, Schöbel T, Fischer J-P et al (2019) Acromioclavicular joint reconstruction: an additional acromioclavicular cerclage does not improve horizontal stability in double coraco-clavicular tunnel technique. Knee Surg Sports Traumatol Arthrosc. https://doi.org/ 10.1007/s00167-019-05674-1

13. Martetschlager F, Saier T, Weigert A et al (2016) Effect of coracoid drilling for acromioclavicular joint reconstruction techniques on coracoid fracture risk: a biomechanical study. Arthroscopy 32:982-987. https://doi.org/10.1016/j.arthro.2015.11.049

14. Clavert $P$, Meyer A, Boyer $P$ et al (2015) Complication rates and types of failure after arthroscopic acute acromioclavicular dislocation fixation. Prospective multicenter study of 116 cases. Orthop Traumatol Surg Res 101:S313-S316. https://doi.org/10.1016/j. otsr.2015.09.012

15. Coale RM, Hollister SJ, Dines JS et al (2013) Anatomic considerations of transclavicular-transcoracoid drilling for coracoclavicular ligament reconstruction. J Shoulder Elbow Surg 22:137-144. https://doi.org/10.1016/j.jse.2011.12.008

16. Kraus N, Haas NP, Scheibel M et al (2013) Arthroscopically assisted stabilization of acute high-grade acromioclavicular joint separations in a coracoclavicular Double-TightRope technique: V-shaped versus parallel drill hole orientation. Arch Orthop Trauma Surg 133:1431-1440. https://doi.org/10.1007/ s00402-013-1804-8

17. Hammer N, Löffler S, Feja C et al (2012) Ethanol-glycerin fixation with thymol conservation: a potential alternative to formaldehyde and phenol embalming. Anat Sci Educ 5:225-233. https://doi.org/ 10.1002/ase. 1270

18. Rios CG, Arciero RA, Mazzocca AD (2007) Anatomy of the clavicle and coracoid process for reconstruction of the coracoclavicular ligaments. Am J Sports Med 35:811-817. https://doi.org/ 10.1177/0363546506297536

19. Braun S, Beitzel K, Buchmann S et al (2015) Arthroscopically assisted treatment of acute dislocations of the acromioclavicular joint. Arthrosc Tech 4:e681-e685. https://doi.org/10.1016/j.eats. 2015.07.029

20. Jensen G, Ellwein A, Voigt C et al (2015) Doppel-Button-Fixierung mit minimalinvasiver akromioklavikularer Cerclage: Arthroskopisch-assistierte Versorgung der akuten Schultereckgelenkinstabilitat (Double button Fixation with minimally invasive acromioclavicular cerclage: Arthroscopically-assisted treatment of acute acromioclavicular joint instability). Unfallchirurg 118:1056-1061. https://doi.org/10.1007/s00113-015-0106-8

21. Banffy MB, Uquillas C, Neumann JA et al (2018) Biomechanical evaluation of a single- versus double-tunnel coracoclavicular ligament reconstruction with acromioclavicular stabilization for acromioclavicular joint injuries. Am J Sports Med 46:1070-1076. https://doi.org/10.1177/0363546517752673

22. Saier T, Venjakob AJ, Minzlaff $P$ et al (2015) Value of additional acromioclavicular cerclage for horizontal stability in complete acromioclavicular separation: a biomechanical study. Knee Surg Sports Traumatol Arthrosc 23:1498-1505. https://doi.org/10. 1007/s00167-014-2895-7

23. Beitzel K, Obopilwe E, Apostolakos J et al (2014) Rotational and translational stability of different methods for direct acromioclavicular ligament repair in anatomic acromioclavicular joint reconstruction. Am J Sports Med 42:2141-2148. https://doi. org/10.1177/0363546514538947

24. Nuchtern JV, Sellenschloh K, Bishop N et al (2013) Biomechanical evaluation of 3 stabilization methods on acromioclavicular joint dislocations. Am J Sports Med 41:1387-1394. https://doi. org/10.1177/0363546513484892

25. Harris RI, Vu DH, Sonnabend DH et al (2001) Anatomic variance of the coracoclavicular ligaments. J Shoulder Elbow Surg 10:585-588. https://doi.org/10.1067/mse.2001.118480

26. Harris RI, Wallace AL, Harper GD et al (2000) Structural properties of the intact and the reconstructed coracoclavicular ligament complex. Am J Sports Med 28:103-108. https://doi.org/10.1177/ 03635465000280010201

27. URIST MR (1946) Complete dislocations of the acromiclavicular joint; the nature of the traumatic lesion and effective methods of treatment with an analysis of forty-one cases. J Bone Jt Surg Am 28:813-837

28. Fukuda K, Craig EV, An KN et al (1986) Biomechanical study of the ligamentous system of the acromioclavicular joint. J Bone Joint Surg Am 68:434-440

29. Debski RE, Parsons IM, Woo SL et al. (2001) Effect of capsular injury on acromioclavicular joint mechanics. J Bone Joint Surg Am 83-A: 1344-1351

30. Yoo YS, Tsai AG, Ranawat AS et al (2010) A biomechanical analysis of the native coracoclavicular ligaments and their influence on a new reconstruction using a coracoid tunnel and free tendon graft. Arthroscopy 26:1153-1161. https://doi.org/10.1016/j. arthro.2009.12.031

31. Weiser L, Nüchtern JV, Sellenschloh K et al (2017) Acromioclavicular joint dislocations: coracoclavicular reconstruction with and without additional direct acromioclavicular repair. Knee Surg Sports Traumatol Arthrosc 25:2025-2031. https://doi.org/ 10.1007/s00167-015-3920-1

32. Schär MO, Jenni S, Fessel G et al (2019) Biomechanical comparison of two biplanar and one monoplanar reconstruction techniques of the acromioclavicular joint. Arch Orthop Trauma Surg 139:779-786. https://doi.org/10.1007/s00402-019-03137-3

33. Seo Y-J, Yoo Y-S, Noh K-C et al (2012) Dynamic function of coracoclavicular ligament at different shoulder abduction angles: a study using a 3-dimensional finite element model. Arthroscopy 28:778-787. https://doi.org/10.1016/j.arthro.2012.04.001

34. Campbell ST, Heckmann ND, Shin S-J et al (2015) Biomechanical evaluation of coracoid tunnel size and location for coracoclavicular ligament reconstruction. Arthroscopy 31:825-830. https://doi. org/10.1016/j.arthro.2014.11.037

35. Theopold J, Weihs K, Löffler S et al (2015) Image-free navigated coracoclavicular drilling for the repair of acromioclavicular joint dislocation: a cadaver study. Arch Orthop Trauma Surg 135:10771082. https://doi.org/10.1007/s00402-015-2243-5

36. Theopold J, Marquass B, von Dercks N et al (2015) Arthroscopically guided navigation for repair of acromioclavicular joint dislocations: a safe technique with reduced intraoperative radiation exposure. Patient Saf Surg 9:41. https://doi.org/10.1186/ s13037-015-0087-0

Publisher's Note Springer Nature remains neutral with regard to jurisdictional claims in published maps and institutional affiliations. 